\title{
Night sedation in the admission wards of a psychiatric hospital
}

\author{
Richard P. W. Fry, Research Registrar in Psychiatry, St George's Hospital Medical \\ School, Cranmer Terrace, London, SW17
}

Since their introduction in the 1960 s, benzodiazepine drugs have been widely prescribed for anxiety states and insomnia. Despite the initial hopes for these drugs being non-addictive and not producing tolerance, recent work has shown that there is a well defined withdrawal syndrome (Hallstrom \& Lader, 1981; Petursson \& Lader, 1981; Tyrer et al, 1981; Tyrer et al, 1983) and that tolerance has also been shown to occur (Aranko et al, 1983; Aranko et al, 1985). There has been widespread concern about these effects. The British National Formulary advocates that "used as hypnotics routine prescribing especially in hospitals is undesirable, and ideally they should be reserved for short courses of treatment in the acutely distressed" and that they should be discontinued as soon as possible. Indeed the Royal College of Psychiatrists' statement on benzodiazepine prescribing and the Committee on Safety of Medicines have recommended that their use as hypnotics should be considered only when the condition is severe, disabling or subjecting the individual to extreme distress. Tyrer \& Murphy (1987) have recommended that these drugs are best used for no longer than two weeks in regular dosage.

It was decided to survey the prescription of night sedation within a large psychiatric hospital, given that benzodiazepines appear to be the most commonly prescribed class of drugs for this purpose. Within the hospital there is a high doctor to patient ratio, and a high level of awareness of current issues in prescribing among both senior and junior staff.

\section{The study}

A survey of all patients in acute adult admission wards in one particular day was undertaken. Admissions of the elderly mentally ill were excluded. This allowed a point prevalence of night sedation prescriptions to be obtained. Data obtained were: age, date of admission, whether on night sedation, whether regular or as required, type, duration, whether admitted on it or started during this admission, and, if started on it this admission, whether rationale for prescription was recorded. Sources of this information were drug charts, patient register boards in wards, and hospital case-notes.
In addition, as many of the prescribing psychiatrists involved as possible were interviewed about the rationale, and their policies and attitudes towards prescription of night sedation. This was not possible for all patients as some doctors had concluded their employment within the hospital. The doctors were first asked about the specific patients and then about more general attitudes. Particular attention was paid to the role of nursing staff in the decision to prescribe, and the doctors' policy concerning admissions and discharges on night sedation.

\section{The findings}

One hundred and fifty-seven patients were in the admission wards at the time of the survey. Of these, $62(39.5 \%)$ patients received night sedation on the night of the survey. Thirty-six $(22.9 \%$ of all acute patients; $58 \%$ of those on night sedation) patients had been started on this hypnotic medication since admission to hospital. The remainder, 26 (16.6\% of all acute patients, $41.9 \%$ of those on night sedation) patients, had been admitted already taking it.

Twenty-two (61.1\%) of the 36 started on night sedation since admission were started on the night of admission. The other 14 had durations of admission ranging from 17 to 335 days (mean 122.5 days) at point of survey, and had been started between 3 and 245 days (mean 42.3 days) after admission. Temazepam was the commonest form of night sedation in patients newly started on a hypnotic (24). The remainder were all on chloral hydrate (12). All such night sedation was on an as required basis. The ages of the patients who were newly started on medication did not appear different from the age of those patients who had received benzodiazepines outside hospital.

It was possible to interview 13 of the SHOs and registrars who had prescribed medication for patients in the study, and they had prescribed for 22 of the 36 patients commenced on hypnotics following admission. The remaining 14 patients had been prescribed for by 10 other doctors who were not available for interview for the reasons given above. 
The main reasons given for prescribing this medication were:

\begin{tabular}{|c|c|c|}
\hline Insomnia & $\begin{array}{c}\text { doctors } \\
5\end{array}$ & $\begin{array}{c}\text { patients } \\
5\end{array}$ \\
\hline Hypomania & 4 & 4 \\
\hline "Disturbed" & 3 & 4 \\
\hline $\begin{array}{l}\text { Policy decision to prescribe } \\
\text { routinely for all admissions }\end{array}$ & 3 & 6 \\
\hline $\begin{array}{l}\text { Nursing staff request } \\
\text { Concern that nursing staff } \\
\text { would request night sedation } \\
\text { during the night }\end{array}$ & 11 & 19 \\
\hline
\end{tabular}

NB Often more than one reason for starting was given.

There was clear agreement from all that a significant motivation for prn prescription was a desire on the doctor's part not to be disturbed by nursing staff during the night.

Other points that emerged were:

(a) Night sedation was often not recorded in admission drug histories.

(b) A clear decision with rationale had been recorded for eight. In most cases there was no record about the commencement of hypnotics.

(c) Night sedation was frequently prescribed simultaneously with new prescriptions for sedative antidepressants or neuroleptics.

(d) Discharge summaries did not usually mention night sedation status or recommendation about future prescription.

All 13 doctors who took part in the survey answered questions on their general policies for future prescribing habits. All expressed the view that they would attempt to ensure night sedation was not handed out indiscriminately.

Five $(38.5 \%)$ of the doctors routinely discharged patients from hospital on night sedation. Three $(23 \%)$ discharged patients on a reducing dose. Three $(23 \%)$ stopped the medication at discharge. Two $(15.5 \%)$ expressed the view that they would always try to decrease it in a stepwise fashion before discharge. On this basis 16 of the 22 newly-commenced patients $(72.7 \%)$ would be discharged on night sedation. All were interested to be asked about policies on this issue as all agreed they had received no formal instruction in this area.

\section{Comment}

Despite public concern and the attempts of various authorities to draw attention to the problems surrounding the prescription of benzodiazepines, it appears that a significant number of patients are started on them following admission to psychiatric hospital (22.9\% in this survey). In many patients this prescription may be continued at discharge $\mathbf{7 2 . 7 \%}$ in this survey). In only $36.1 \%$ (13 of 36 ) was this medication prescribed in response to the patient's clinical state. If this sample is representative of the country in general, then there may be cause for concern. It may be, of course, that in a situation where senior rather than junior trainee psychiatrists are responsible for such prescriptions the pattern would be different, as might pertain, for example, in a consultant-based service. It may also be that there is an opening for more formalised teaching and formulation of policies in this area among both medical and nursing staff. The other point that emerges from this small survey is that clinical audit such as this is relatively easy and non time-consuming to perform. A final point is that traditionally GPs have been in the forefront of criticism about prescription of benzodiazepines; surveys like this reveal the need for an awareness of our own prescribing habits as well.

\section{Acknowledgement}

I would like to thank my colleagues for their cooperation and help with this survey.

\section{References}

Aranko, K., Mattilsa, M. \& Seppala, T. (1983) Development of tolerance and cross tolerance to the psychomotor actions of lorazepan and diazepam in man. British Journal of Clinical Pharmacology, 15, 545-552.

-, -, Nuutilla, A. \& Pelunen, J. (1985) Benzodiazepines, but not antidepressants or neuroleptics, induce dose-dependent development of tolerance to lorazepam in psychiatric patients. Acta Psychiatrica Scandinavica, 72, 436-446.

British National Formulary, 15, (1988) p. 136. Londo:: British Medical Association and The Pharmaceutical Society.

Hallstrom, C. \& Lader, M. H. (1981) Benzodiazepine withdrawal phenomena. International Pharmacopsychiatry, 16, 235-244.

Petursson, H. \& Lader, M. H. (1981) Withdrawal from long-term benzodiazepine treatment. British Medical Journal, 283, 643-645.

Royal College of Psychiatrists (1988) Benzodiazepines and dependence: a College Statement. Bulletin of the Royal College of Psychiatrists, 12, 107-108.

TYRER, P. \& MURPHY, S. (1987) The place of benzodiazepines in psychiatric practice. British Journal of Psychiatry, 151, 719-723.

-, OWEN, R. \& DAWLING, S. (1983) Gradual withdrawal of diazepam after long therapy. Lancet, i, 1403-1406.

-, RUTHERFORD, D. \& HUGGETT, T. (1981) Benzodiazepine withdrawal symptoms and propranolol. Lancet, i, 520522 